Open Access to Pharmaceutical and Medical Research
(C) 2011-18, publisher and licensee JDDT, This is an Open Access article which permits
unrestricted non-commercial use, provided the original work is properly cited

Open 2 Access

Research Article

\title{
Disintegrant Properties of Native Starches obtained from Cassava, Sweet Potato and Corn in Ibuprofen Tablet Formulations
}

\author{
Nkemakolam Nwachukwu 1*, Edwin Aboje Ubieko² \\ ${ }^{1}$ Department of Pharmaceutics and Pharmaceutical Technology, Faculty of Pharmaceutical Sciences, University of Port Harcourt, Choba, Rivers \\ State, Nigeria \\ ${ }^{2}$ Department of Pharmaceutics and Industrial Pharmacy, Faculty of Pharmacy, Madonna University, Elele, Nigeria
}

\begin{abstract}
This study is aimed at evaluating the disintegrant properties of starches obtained from cassava (Manihot esculenta), sweet potato (Ipomoea batatas) and yellow corn (Zea mays). Matured tubers of cassava and potato were peeled, cut into smaller pieces, wet milled and their slurries washed severally with distilled water to obtain cassava and potato starches respectively. Matured seeds of yellow corn were steeped in distilled water for $24 \mathrm{~h}$, wet milled and washed to separate the starch from the cellulose. The starches were dried at $50{ }^{\circ} \mathrm{C}$ after which they were characterized using standard methods. The starches at $10 \% \mathrm{w} / \mathrm{w}$ were applied as disintegrants in the formulation of metronidazole tablets using wet granulation technology. Corn starch (British Pharmacopoeia) at $10 \% \mathrm{w} / \mathrm{w}$ was used as comparing standard. The ibuprofen granules were evaluated for their micromeritic properties and thereafter compressed into ibuprofen tablets. Evaluation of the ibuprofen tablets for their physical properties, assay and dissolution studies were done using British Pharmacopoeia methods. Results showed that the materials extracted were starches, and they had a poor flow. The ibuprofen granules were flowable and compressible. Ibuprofen tablets compressed from these granules had good physical properties: minimal weight variation $(604.00 \pm 0.04-606.00 \mathrm{mg} \pm 0.03 \%)$, hardness $(5.32 \pm 0.41-6.33 \pm$ $0.64 \mathrm{kgF}$ ), disintegration time $<15.00 \mathrm{~min}$ and friability $<1.00 \%$. Assay and dissolution of metronidazole from the tablets complied with British Pharmacopoeia criteria. Cassava, potato, and yellow corn starches served as good disintegrants in ibuprofen tablet formulatio ns.
\end{abstract}

Keywords: Disintegrant, starch, cassava, potato, corn, ibuprofen tablets

Article Info: Received 13 July 2020； Review Completed 28 August 2020; $\quad$ Accepted 06 Sep 2020; $\quad$ Available online 15 Sep 2020

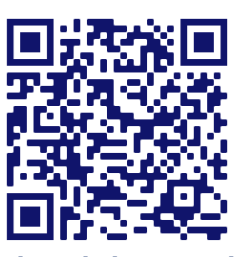

\section{Cite this article as:}

Nwachukwu N, Ubieko EA, Disintegrant Properties of Native Starches obtained from Cassava, Sweet Potato and Corn in Ibuprofen Tablet Formulations, Journal of Drug Delivery and Therapeutics. 2020; 10(5):264-273 http://dx.doi.org/10.22270/jddt.v10i5.4324

\section{*Address for Correspondence:}

Nkemakolam Nwachukwu, Department of Pharmaceutics and Pharmaceutical Technology, Faculty of Pharmaceutical Sciences, University of Port Harcourt, Choba, Rivers State, Nigeria

\section{INTRODUCTION}

The orally ingested pharmaceutical tablet remain the most popular dosage form in drug delivery, while the oral route remains the most frequently used route for administration of therapeutic agents 1 . This popularity is connected to the many advantages of tablet dosage form which includes accurate dosage administration of the drug, ease of selfmedication which promotes a high degree of patient compliance, high level of therapeutic response and good shelf life of the product. The pharmaceutical tablet is often formulated with the active pharmaceutical ingredient (API) in combination with excipients that can enhance the functionality of the dosage form. Conventional or normal release tablet dosage forms are formulated in a manner that would permit the tablet to break up (disintegrate) and release its API as soon as the tablet has been ingested and is resident in the stomach ${ }^{2}$. Disintegrants can be described as non-active pharmaceutical agents that are added to tablet formulations to encourage the break-up of the tablet into smaller fragments in an aqueous environment, which would result to an increased surface area thus promoting a more rapid release of the drug substance contained in the tablet for dissolution and absorption 3,4. Disintegration occurs when the physiological fluid penetrates into the tablet/compact which will lead to disruption of the particleparticle bonds which is responsible for the mechanical strength as well as the structural integrity of the dosage form. Research and advances in excipient development in recent times have led to the development of many new disintegrants which are capable of enhancing disintegration irrespective of their application in small quantities in tablet formulations 5. Disintegrants are available in both the natural or synthetic forms. The popular and commercially available natural disintegrants include the starches and gellan gum while the synthetic ones include polyvinylpyrrolidone, modified starches and cellulose, primogel, crosspovidone, etc. ${ }^{6}$. 
Starch is a common, naturally occurring biomass material that is synthesized in most green plants which contain chlorophyll through the process of photosynthesis 7 . Its storage in plants is not restricted to any part of the plant as it has been found to be widely distributed within the different parts of a plant such as the leaves of green plants, seeds, fruits, stems, roots, and tubers. However, the type of plant where the starch is synthesized would greatly influence its level of distribution and storage within the plant. In the green leaves, starch is formed in the chloroplasts while in fruits and tubers, it is formed in the amyloplasts of seeds, fruits and tubers. However, despite the site of formation and storage in the plant, starch is consumed as food by animals, especially by man. Starch is richly stored in the grains of cereal crops such as wheat, corn or maize, soybean, millet, rice and in roots of potato and cassava, tubers of yam, etc. ${ }^{8}$. Besides the use of starch as food, it is also employed in the textile industry as stiffening agent in fabrics, while the food and cosmetic industry use it as a thickener. In the paint industry it has played the role of filler and thickener ${ }^{7}$.

Manihot esculenta Crantz (Family: Euphorbiaceae) is most commonly known as cassava, although other names such as tapioca and manioc are also used to describe it ${ }^{9}$. It is a tropical perennial plant that grows in lowlands and is known to be rich in starch which is stored mostly in its root tubers. In Nigeria, it is a staple food that is processed as either garri, fufu or flakes. In the confectionary industry, it is used as flour for baking bread, biscuits, cakes or other snacks. In the pharmaceutical industry, cassava starch can be used as a binder, filler/diluent and disintegrant 10.

Ipomoea batatas, popularly known as sweet potato (Family: Convolvulaceae), is an important food crop that grows well in the tropics, subtropics and warm temperate regions of the world. Its edible tubers are rich in starch and cellulose amongst other components. Besides cassava, it is the second most popularly consumed tuberous crop in the tropics 11-14.

Zea mays L (maize or corn) are an annual crop belonging to the grass family Poaceae and is widely cultivated globally although it originated from Mexico ${ }^{15}$. Its matured seeds are used as food for man or livestock in many countries of the world including Nigeria. It is also gainfully used in the preparation of pharmaceutical tablets where it plays a multifunctional role as either a binder, bulking agent and/or disintegrant.

Ibuprofen is a drug which possesses anti phlogistic (anti pyretic and anti-inflammatory) and analgesic properties. It is a member of the non-steroidal anti-inflammatory drugs (NSAIDs). It is readily absorbed from the gastrointestinal tract and has an onset of action of approximately $30-60$ min with a duration of action of 6 - 8 h 16-20. Its mechanism of action is by inhibiting a class of enzymes called cyclooxygenases (COX). Cyclooxygenases catalyze the synthesis of prostaglandins. Prostaglandins which is synthesized everywhere in the body, has both positive and negative effects. Also a particular prostaglandin may act differently depending on the tissue where it is found as well as the availability of a receptor the prostaglandin gets bound to. They mediate the responses of pain, inflammation etc. as negative effects to the body. One of its derivatives, prostacyclins acts by preventing aggregation of blood platelet and as a vasodilator from where it has the role of inflammation. The other derivative, thromboxane is produced by platelet cells and unlike prostacyclins are vasoconstrictors and facilitate blood platelet aggregation.
Ibuprofen is practically slightly soluble in water and has poor flow and compaction characteristics owing to its needle-like (acicular) crystalline structure and viscoelastic properties respectively. Ibuprofen is a core medicine in WHO's "Essential Medicines List" which is a list of essential medicines that satisfy the minimum medical needs for a basic health care system 21 .

Although many substances of both natural and synthetic origin are commercially available and used as disintegrants, starch especially derived from corn have continued to be used as a disintegrant in tablet formulations. In Nigeria, many starches especially of local origin have been mostly used as food while a great percentage of starches for pharmaceutical use have been imported. This work is targeted at comparatively evaluating the disintegrant properties of starches obtained from locally grown cassava, yellow corn and sweet potato in the formulation of ibuprofen tablets and to compare them with corn starch British Pharmacopoeia, a commercially available starch.

\section{MATERIALS AND METHODS}

The following materials were used as procured: Ibuprofen powder (Boai Nky, China), Sodium hydrogen carbonate and Lactose (Surechem, England), Magnesium stearate (Boai, Nky, China), Talc (Boai, Nky, China), Acacia, Gelatin (J.T Bayer, USA) and Corn starch BP (BDH, England). cassava, potato and yellow corn starches were locally prepared.

\section{Procurement of samples}

The matured root tubers of cassava (Manihot esculenta), sweet potato (Ipomoea batatas) and matured seeds of yellow maize/corn were bought from the Mile 3 market, Port Harcourt in sufficient quantities. The different crop samples were identified and authenticated by a taxonomist, Dr. Ekeke Chimezie, of the University of Port Harcourt herbarium. Voucher specimens were deposited at the University of Port Harcourt herbarium.

\section{Processing of samples}

\section{Cassava}

A quantity of $1.50 \mathrm{~kg}$ of cassava root tubers were washed with water and the outer back peeled off. The tubers were cut into smaller pieces and were wet milled with distilled water in a corn mill (Corona, China). Using a muslin cloth, the cassava slurry was washed with distilled water in order to separate the starch from the cellulose (fibre). The cassava starch passed through the muslin cloth while the fiber (cellulose) was retained on it. The starch was allowed to sediment, the supernatant was decanted and after two more washings, sedimentation and decanting of supernatant, excess water was pressed out and the damp starch spread on trays and dried in the oven (Memmert, England) at $50{ }^{\circ} \mathrm{C}$ until it was sufficiently dried. The dried cassava starch was stored in an airtight container for further use.

\section{Potato starch}

A $1.20 \mathrm{~kg}$ quantity of Ipomoea balatas tuber was peeled, washed with portable water, cut into smaller pieces and milled into paste/slurry. The paste/slurry was washed with distilled water through a muslin cloth to separate the cellulose from the starch. The starch was washed severally and dried to a constant weight in an oven (Memmert, England) at $50{ }^{\circ} \mathrm{C}$ until it was properly dried.

\section{Yellow corn/maize}

A quantity of $1.00 \mathrm{~kg}$ of corn seeds were steeped in distilled water for $24 \mathrm{~h}$, after which the water was drained off, and 
the seeds wet milled using a corn milling machine (Corona, China) to obtain a finely milled slurry. The slurry was placed in a muslin bag and was washed with distilled water. The filtrate (starch) was received in a container while the fiber (cellulose) was retained on the muslin bag. The starch slurry was allowed to sediment in the container, then the supernatant was decanted and the wet starch placed in a muslin bag which was squeezed to remove more water from it. The damp starch was collected and dried in an oven at 50 ${ }^{\circ} \mathrm{C}$. It was screened through a $180 \mu \mathrm{m}$ (micrometer) stainless steel sieve and stored in an airtight container.

\section{Characterization of the Starches}

\section{Organoleptic properties determination of the starches}

The different starch samples were evaluated for some of their organoleptic properties such as texture, colour, and odour.

\section{Identification test}

The starches extracted from the different plants were subjected to a basic iodine test. A 0.20 g quantity each of the cassava, potato and yellow corn starches were placed separately on a white tile/slab and a few drops of iodine solution dropped on the powders ${ }^{22}$. They were observed for any changes in colour.

\section{pH determination}

A $2 \mathrm{~g}$ quantity of each starch from the cassava, potato and yellow corn were dispersed in water to form a $2 \% \mathrm{w} / \mathrm{v}$ dispersion. A pH meter (Hannah, USA) was calibrated and inserted into each of the starch dispersions to determine the $\mathrm{pH}$. Triplicate determinations were done and the results obtained recorded.

\section{Solubility determination}

The solubility of the different starches was investigated by dispersing $2 \mathrm{~g}$ samples of these starches in $100 \mathrm{ml}$ of water, ethanol and acetone. Their solubility's in the different test media were visually observed and noted.

\section{Gelation}

A 2 g quantity of each starch was dispersed in $100 \mathrm{ml}$ of cold water and then heated in a water bath up to $70{ }^{\circ} \mathrm{C}$. It was observed for any physical change of the dispersion into a gel.

\section{Elemental analysis}

Each of the starch powders was analyzed for the presence of heavy metals such as Lead (Pb), Iron (Fe), Zinc (Zn), Manganese (Mn) and Arsenium (As) using an Atomic absorption spectroscope, AAS Model AA-7000, ROM version 1.01, S/N A30664700709 (Shimadzu ${ }^{\circledR}$, Japan) at wavelengths of 283.30, 248.30, 213.90, 279.50 and 193.70 $n m$ respectively.

\section{Hydration capacity determination}

The hydration capacity of the starch powders was determined using the method developed by Kornblum and Stoopaks 23 with slight modification. A quantity of $1 \mathrm{~g}$ of each of the sample was put in a $15 \mathrm{ml}$ plastic centrifuge tube and $10 \mathrm{ml}$ of distilled water added to it. Each tube was shaken intermittently over a $2 \mathrm{~h}$ period and left to stand for $30 \mathrm{~min}$. Centrifugation at 1000 revolutions per minute (rpm) was done for $10 \mathrm{~min}$ using a centrifuge model TX 150 (Thermo Fisher Scientific, UK). The supernatant layer of the dispersion was carefully decanted and the wet sediment weighed. The hydration capacity was calculated using equation 1:

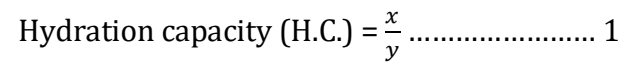

Where $\mathrm{x}=$ weight of wet sample/ powder sediment and $\mathrm{y}=$ weight of dry sample/powder.

\section{Swelling index determination}

The swelling capacity of the cassava, potato and yellow corn starch powders were determined using the method of Bowen and Vadino ${ }^{24}$ with slight modification. A 3 g quantity of the starch sample was placed in a $100 \mathrm{ml}$ graduated glass measuring cylinder and tapped to obtain the tapped volume, $\mathrm{V}_{\mathrm{t}}$. A dispersion of the powdered sample was made in $85 \mathrm{ml}$ of water and this was shaken thoroughly. The volume was made up to $100 \mathrm{ml}$ with water. The mixture was allowed to stand undisturbed for $24 \mathrm{~h}$ on a flat surface and the volume of the sediment formed, $V_{\mathrm{v}}$ noted. Triplicate determinations were done for each of the samples and the swelling capacity calculated using equation 24 .

$$
\text { Swelling capacity (S.C.) }=\frac{v v-v t}{v t} \times 100 \ldots \ldots \ldots . . .2
$$

\section{FORMULATION OF IBUPROFEN GRANULES}

Ibuprofen granules were formed using the ingredients shown in Table 1 . An amount of each of the ingredients that was required for the production of 100 tablets from the granules was calculated, weighed out (except talc and magnesium stearate), added using the doubling up technique, blended to homogeneity and wet granulated. A solution of the gelatin was used as the granulating fluid. The granules were formed by wet screening the damp mass of ibuprofen and the other excipients through a $2 \mathrm{~mm}$ sieve, dried in the oven [Memmert, England] at $60{ }^{\circ} \mathrm{C}$ for $1 \mathrm{~h}$, rescreened through a $1 \mathrm{~mm}$ sieve, further dried at $60{ }^{\circ} \mathrm{C}$ in the oven until a constant weight was attained.

Table 1: Formula for ibuprofen tablets

\begin{tabular}{lllll}
\hline Ingredient & Batch I & Batch II & Batch III & Batch IV \\
\hline Ibuprofen (mg) & 400.00 & 400.00 & 400.00 & 400.00 \\
Cassava starch (mg) & 60.00 & 0.00 & 0.00 & 0.00 \\
Potato starch (mg) & 0.00 & 60.00 & 0.00 & 0.00 \\
Yellow corn starch (mg) & 0.00 & 0.00 & 60.00 & 0.00 \\
Corn starch BP (mg) & 0.00 & 0.00 & 0.00 & 60.00 \\
Gelatin (mg) & 9.00 & 9.00 & 9.00 & 9.00 \\
Talc (mg) & 3.00 & 3.00 & 3.00 & 3.00 \\
Magnesium stearate(mg) & 3.00 & 3.00 & 3.00 & 3.00 \\
Lactose (mg) & 125.00 & 125.00 & 125.00 & 125.00 \\
Total (mg) & 600.00 & 600.00 & 600.00 & 600.00 \\
\hline
\end{tabular}




\section{Characterization of ibuprofen granules}

Granules of the different ibuprofen formulations containing the different starches: cassava, potato, yellow corn and corn starch BP (represented as batches I, II, III and IV respectively) were evaluated for their bulk and tapped densities, flow rate, angle of repose, Hausner's quotient, Carr's Compressibility index, true density and porosity.

\section{Bulk and Tapped densities}

A quantity of $20 \mathrm{~g}$ of the respective granules of ibuprofen containing cassava, potato and yellow corn starches were individually poured into a $200 \mathrm{ml}$ graduated glass measuring cylinder of a Stampfvolumeter (STAV 2003JEF, Germany) with the aid of a glass funnel. The equipment was set to operate at 500 taps and bulk and tapped volumes determined. Determinations for each of the granules was done in replicates and the bulk and tapped densities were calculated using equations 3 and 425 .

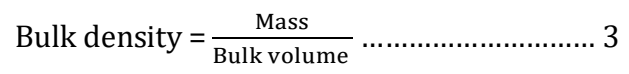

$$
\begin{aligned}
& \text { Tapped density }=\frac{\text { Mass }}{\text { Tapped volume }} \ldots \ldots \ldots \ldots \ldots \ldots \ldots \ldots . . . . . . . . . . .4
\end{aligned}
$$

\section{True density}

The True density of each of the respective ibuprofen granules was determined by solvent displacement method using n-hexane 26 . A tarred $50 \mathrm{ml}$ pycnometer (W) was filled with $n$-hexane and the weight noted as (W1). The weight of the n-hexane was obtained by subtracting $\mathrm{W}$ from W1. A quantity of $1 \mathrm{~g}$ of ibuprofen granule (W3) and was transferred into the pycnometer, the excess n-hexane displaced from the pycnometer was wiped off the body of the pycnometer and the pycnometer and its content was weighed again (W4). Replicate determinations were done for each batch of ibuprofen granules. The True density, Pt was calculated using equation 526 .

$$
P t=\frac{W 2 \times W 3}{V(W 3-W 4+W 2+W)} \ldots \ldots \ldots .
$$

where $V$ is the volume of the pycnometer. Triplicate determinations were done for each of the ibuprofen formulation.

\section{Flow rate and angle of repose}

The flow rate and angle of repose of the ibuprofen granules was determined by using a modification of the Jones and Pilpel method 27. A quantity of $20 \mathrm{~g}$ of the ibuprofen granules was poured into a funnel that was clamped with the orifice of the efflux tube at a height of $3 \mathrm{~cm}$ above a flat surfaced platform. The orifice was closed with a metric rule to prevent premature discharge of the granules. On removal of the metric rule, the time it took for the granules to be completely discharged from the funnel was noted. Replicate determinations were done for each of the powders. The flow rate was determined using equation 6 .

$$
\text { Flow rate }=\frac{\text { mass of powder }}{\text { time }}
$$

The height and diameter of the base of the heap of granule formed on the platform was measured and the angle of repose calculated using equation 7 :

$$
\text { Angle of repose, } \theta=\tan ^{-1} \frac{2 h}{d} \text {... }
$$

where $\theta$ is the angle of repose, $h$ is the height of heap of powder, $d$ is the diameter of the heap of powder.

\section{Hausner's quotient and Carr's Index}

The Hausner's quotient was calculated as the ratio of tapped density to bulk density of the powder as shown in equation 8 while the Carr's Index (CI) is determined from equation 928.

$$
\begin{aligned}
& \text { Hausners quotient }=\frac{\text { tapped density }}{\text { bulk density }} \ldots \ldots \ldots \\
& \mathrm{CI}=\frac{\text { tapped density }- \text { bulk density }}{\text { tapped density }} \times 100 \ldots
\end{aligned}
$$

\section{Porosity}

Porosity depicts the volume/pores present relative to the tapped volume that was used to calculate the tapped density. The porosity of ibuprofen granules depicts the number of intra and interparticulate void spaces that exists within the granules and is determined using equation 1029 .

$$
\text { Porosity }=1-\left[\frac{\text { Bulk density }}{\text { particle density }}\right] \times 100 \ldots \ldots \ldots
$$

\section{Compression of ibuprofen tablets}

The ibuprofen granules containing starches of cassava, potato, yellow corn and corn starch BP (Table 1) were compressed into ibuprofen tablets. The talc and magnesium stearate were added immediately prior to compression. A single station Manesty tablet press, Model F-3 (Manesty, England) fitted with a set of flat faced punches $(12.5 \mathrm{~mm}$ diameter) and dies at a compression pressure of $9.81 \mathrm{kN}$ was used to compress 200 tablets per batch at a target tablet weight of $600 \mathrm{mg}$ per tablet and dwell time of $20 \mathrm{sec}$.

\section{Characterization of Ibuprofen Tablets}

The ibuprofen tablets were characterized $24 \mathrm{~h}$ after they were tableted for their physical properties, content of active ingredient and drug release from the tablets using pharmacopoeia methods.

\section{Physical appearance}

The tablets were visually examined to determine their colour, shape and whether defects such as chipping or capping occurred.

\section{Uniformity of weight of tablets}

The ibuprofen tablets were checked for variation in tablet weight by randomly selecting and individually weighing 20 tablets from each batch of the formulation

\section{Hardness}

Through a process of random selection, 10 tablets from each batch of the ibuprofen formulation was collected and a model TBH 100 hardness tester (Erweka, Germany) was used to determine pressure at which each tablet diametrically broke.

\section{Disintegration time}

The disintegration time of the ibuprofen tablets were determined by randomly selecting six tablets from each batch of the formulation and putting each tablet from any given batch into each of the six cylindrical holes of a model ZT-122 disintegration machine (Erweka, Germany). The disintegration medium was $500 \mathrm{ml}$ of $0.1 \mathrm{~N} \mathrm{HCl}$ held in a $1 \mathrm{~L}$ beaker that was immersed in a water bath. The temperature of both the medium and bath were maintained at $37 \pm 0.5^{\circ} \mathrm{C}$. The machine was switched on and disintegration was said to have taken place when the entire tablet has been broken down into small fragments which are not retained on the mesh at the bottom of the cylindrical hole. If any mass is retained, it must not be a firm palpable core of the tablet 
used for the test but could belong to insoluble materials used in the tablet formulation 30 .

\section{Friability}

Ten tablets that were randomly selected from each batch of the ibuprofen tablet formulations were freed of dust, collectively weighed $(W i)$ and put into one of the drums of the friability tester, model TAR 200 (Erweka, Germany). The machine was operated in a way that the drum rotated at 25 rotations per minute $(\mathrm{rpm})$ for $4 \mathrm{~min}$. The tablets were collected, de-dusted and reweighed (Wf) 30 and the percentage friability $(\mathrm{F})$ calculated using equation 11 :

$$
\mathrm{F}=\left[1-\frac{W f}{W i}\right] \times 100
$$

\section{Thickness}

Ten tablets were picked at random from each brand of the ibuprofen tablets. The thickness and diameter of the tablets were individually determined using a micrometer screw gauge. The mean and standard deviation for each determination was recorded.

\section{Hardness Friability Ratio}

The hardness friability ratio is calculated as a ratio between the hardness and friability of each set of ten tablets that were evaluated from each batch of the ibuprofen tablet formulation.

\section{Determination of maximum wavelength of absorption of ibuprofen}

A $100 \mathrm{mg} / \mathrm{ml}$ stock ibuprofen solution was prepared by dissolving $100 \mathrm{mg}$ of the reference ibuprofen powder in sufficient quantity of phosphate buffer ( $\mathrm{pH} \mathrm{7.2)} \mathrm{in} \mathrm{a} 100 \mathrm{ml}$ volumetric flask, and making up to the $100 \mathrm{ml}$ volume using the $\mathrm{pH} 7.2$ phosphate buffer. A portion of the prepared solution was scanned in a UV/Vis spectrophotometer model 6405 (Jenway, UK) to obtain the maximum wavelength of absorption at Pure $224 \mathrm{~nm}$.

\section{Standard calibration (Beer's plot)}

Serial dilutions of the stock were made to obtain concentrations of $2,4,6,8$ and 10 micrograms $/ \mathrm{ml}(\mu \mathrm{g} / \mathrm{ml})$. The absorbance readings of these different diluted ibuprofen solutions were obtained using the spectrophotometer at an absorbance of $224 \mathrm{~nm}$. A plot of the absorbance readings against the different concentrations was made. The standard calibration equation was determined.

\section{Assay/content of active ingredient determination}

Assay of the ibuprofen tablets was done using the British Pharmacopoeia method 30. Twenty tablets each of the ibuprofen tablets formulated with the different starches were randomly selected and weighed collectively to determine their total weight. They were pulverized to very fine powder and the quantity equivalent to the mean weight of one tablet was taken and dispersed in a $\mathrm{pH} 7.2$ phosphate buffer solution in a $100 \mathrm{ml}$ volumetric flask. The contents were properly shaken, after which they were filtered through a filter paper. A hundred fold dilution of the filtrate was made and its absorbance determined at a wavelength of 224 $\mathrm{nm}$ using a UV/Vis spectrophotometer model 6405 (Jenway ${ }^{\circledR}$, UK). Triplicate determinations were made. This was done for all the batches.

\section{Dissolution of ibuprofen}

The dissolution of ibuprofen or its release profile from the tablets were carried out using a six station model DT 600 disintegration apparatus (Erweka ${ }^{\circledR}$, Germany). A tablet from each batch was individually put in $900 \mathrm{ml}$ of phosphate buffer ( $\mathrm{pH}$ 7.2) solution contained in a $1 \mathrm{~L}$ flask kept in a water bath whose temperature was maintained at $37 \pm 0.5^{\circ} \mathrm{C}$ with a paddle speed set at $50 \mathrm{rpm}{ }^{30}$. Five $\mathrm{ml}$ samples were withdrawn from the test media every $10 \mathrm{~min}$ and filtered through a filter paper. Five $\mathrm{ml}$ of fresh phosphate buffer $\mathrm{pH}$ 7.2) maintained at the bath temperature was used to replace the withdrawn sample after each sampling time. The filtrates were scanned at wavelength of $224 \mathrm{~nm}$ in the spectrophotometer and the absorbance readings obtained were converted to concentrations using the standard calibration equation earlier established.

\section{Statistical analysis}

Statistical analysis was carried out with the IBM SPSS version 21 (SPSS Inc., Chicago, Illinois, USA) software using one way analysis of variance (ANOVA). Results were considered significant at $\mathrm{p}<0.05$.

\section{RESULTS AND DISCUSSION}

\section{Yield of starches}

The yield of the different starches from the different crops cassava, potato and yellow corn are shown in Table 2. The values for cassava and potato were based on their freshly harvested root tubers while that of yellow corn was based on the dried corn seed. These results conform to earlier reports on the quantity of starch contained by these crops 26,31 .

\section{Physicochemical properties}

\section{Organoleptic properties of starches}

Some results of the organoleptic evaluations of the starches are shown in Table 4 . All the starches were white, odourless and granular powders. These properties are similar to earlier reports by other researchers although variations in colour and texture would depend on the botanical source of the starch 26,32 .

\section{Identification}

Results obtained from the iodine test shows that all the starches changed colour from their initial colours to a dark blue colour. Blue black or dark blue colour is a positive result to the iodine test for the presence of starch which implies that the materials extracted were starches 22,32 .

\section{Solubility}

The starches were seen to be insoluble in ethanol and distilled water (Table 2). Starches are generally known for their insolubility in polar solvents such as water 32 .

\section{Gel formation}

Results of the gelation studies showed that all the aqueous dispersions of the starches gelatinized on heating to temperatures above $70{ }^{\circ} \mathrm{C}$ (Table 2). This is also characteristic of starch materials 32 .

\section{pH}

The $\mathrm{pH}$ of the aqueous dispersions of the different starches is shown in Table 2 . Most of the starches were slightly acidic except yellow corn starch that had a slightly alkaline $\mathrm{pH}$. There was no significant difference $(\mathrm{p}>0.05)$ in $\mathrm{pH}$ of all the starch materials. However, the $\mathrm{pH}$ of the starches was close to a neutral value and this makes the starches good candidates for the formulation of both acidic and alkaline drugs. The knowledge of the $\mathrm{pH}$ of pharmaceutical excipients is necessary as it will aid the drug formulator in choosing the best excipient for any active pharmaceutical ingredient. 


\section{Elemental analysis}

Results from the test of heavy metals and the quantities of such heavy metals, and other non-heavy metals are shown in Table 2. It was observed that heavy metals such as lead, mercury and arsenic were completely absent while metals such as copper, zinc and iron were present within tolerable limits 30. Thus, the environment where the crops that produced these starches were grown, their storage conditions after harvesting, and the processing methods used during extraction were devoid of heavy metal contamination which could lead to toxicity and unwanted health hazards to the consumers of the ibuprofen tablets containing these starches.

\section{Swelling capacity/index}

The result of the swelling capacity of the different starches is shown in Table 2 . The swelling capacity can be stated to be the actual amount of water a material is able to retain after it has absorbed water. In other words, swellablity indicates increase in volume of water taken up after absorption 33 . There was no significant difference $(p>0.05)$ in the swelling index of the cassava, potato and yellow corn starches. However there was a significant difference $(p<0.05)$ in the swelling capacity of corn starch BP. The starch samples retained twice as much water of the tapped volume of their dry powders except for corn starch BP that had up to thrice its initial volume. The species of maize and/or its method of extraction could have been responsible for the higher value obtained with corn starch BP. The swelling index values obtained suggests that these starches would serve as good disintegrants in tablet formulations because they would permit entry of water into the tablet core when hydrated and would subsequently swell up thereby aiding the breakdown of the tablet into fragments. This would cause an increased surface area of the particles and this is a desirable property of an excipient as it ensures that the API of conventional release and uncoated tablets are made available for dissolution and possible absorption.

Table 2: Physicochemical properties of Cassava, potato, yellow corn and corn starch BP

\begin{tabular}{|c|c|c|c|c|c|}
\hline \multicolumn{2}{|c|}{ Parameter/material } & Cassava & Potato & Yellow corn & Corn starch BP \\
\hline \multicolumn{2}{|c|}{ Yield (\%) } & 24.50 & 18.20 & 62.00 & - \\
\hline \multicolumn{2}{|l|}{ Odour } & Odourless & Odourless & Odourless & Odourless \\
\hline \multicolumn{2}{|l|}{ Color } & White & White & White & White \\
\hline \multicolumn{2}{|l|}{ Texture } & Fine & Fine & Fine & Fine \\
\hline \multicolumn{2}{|c|}{ Iodine test } & Dark blue & Dark blue & Dark blue & Dark blue \\
\hline \multicolumn{2}{|c|}{ Solubility } & $\begin{array}{l}\text { Insoluble in } \\
\text { distilled water, } \\
\text { ethanol and } \\
\text { acetone }\end{array}$ & $\begin{array}{l}\text { Insoluble in } \\
\text { distilled water, } \\
\text { ethanol and } \\
\text { acetone }\end{array}$ & $\begin{array}{l}\text { Insoluble in } \\
\text { distilled water, } \\
\text { ethanol and } \\
\text { acetone }\end{array}$ & $\begin{array}{l}\text { Insoluble in } \\
\text { distilled water, } \\
\text { ethanol and } \\
\text { acetone }\end{array}$ \\
\hline \multicolumn{2}{|c|}{ Gel formation } & Positive & Positive & Positive & Positive \\
\hline \multicolumn{2}{|l|}{$\mathrm{pH}$} & $6.90 \pm 0.00$ & $6.50 \pm 0.02$ & $7.10 \pm 0.01$ & $6.90 \pm 0.01$ \\
\hline \multicolumn{2}{|c|}{ Swelling index } & $2.45 \pm 0.15$ & $2.87 \pm 0.28$ & $2.80 \pm 0.35$ & $4.73 \pm 0.23$ \\
\hline \multirow{6}{*}{$\begin{array}{l}\text { Heavy } \\
\text { metals } \\
(\mathrm{ppm})\end{array}$} & Lead (Pb) & 0.00 & 0.00 & 0.00 & 0.00 \\
\hline & Mercury (Hg) & 0.00 & 0.00 & 0.00 & 0.00 \\
\hline & Arsenic (As) & 0.00 & 0.00 & 0.00 & 0.00 \\
\hline & Copper (Cu) & 0.23 & 0.23 & 0.19 & 0.29 \\
\hline & Iron (Fe) & 0.49 & 0.49 & 0.99 & 0.86 \\
\hline & Zinc (Zn) & 0.13 & 0.27 & 0.11 & 0.12 \\
\hline
\end{tabular}

\section{Some Micromeritic Properties of Ibuprofen Granules}

\section{Bulk and Tapped densities}

The results of the bulk and tapped densities of the ibuprofen granule evaluations are shown in Table 3. The tapped densities were consistently higher than the bulk densities for all the ibuprofen granules containing cassava, potato and corn starches which are indicative of volume reduction of the powder bed on agitation. Thus, they can be categorized as compressible granules. There was no significant difference ( $p>0.05)$ in the bulk densities. A similar trend was observed in the tapped densities.

\section{Flow rate}

Table 3 contains the results of the flow rates of the ibuprofen granules. Generally, the granules had good flow attributes and would be good for preparation of ibuprofen tablets with good physical properties such as uniform weight, content and hardness.

\section{Angle of repose}

The angle of repose of the ibuprofen granules are shown in Table 3 and ranged from $27.00 \pm 0.50-30.10 \pm 0.01^{\circ}$. There was a significant difference $(\mathrm{p}<0.05)$ in the angle of repose of ibuprofen granules containing cassava, potato and yellow 
corn starches. However, there was no significant difference ( $p>0.05$ ) between the ibuprofen granules containing yellow corn and corn starch BP. The granules generally can be classified as having an excellent flow 30, 34. Based on their flowability, they would fill the dies properly during tableting, resulting to tablets with minimal variation in weight.

\section{Hausner's quotient and Carr's compressibility Index}

The Hausner's quotient of the ibuprofen granules were in the range of $1.14 \pm 0.01-1.17 \pm 0.01$ and Carr's compressibility in the range of $12.19 \pm 0.91-14.28 \pm 0.33 \%$ (Table 3). Generally, the granules can be classified as having good flow properties 30, 34. These flow indices suggest that the ibuprofen granules would be reasonably discharged from the hopper to the die to aid the formation of well filled and compressed tablets.

\section{Porosity}

The porosity evaluation results of the ibuprofen tablets are shown in Table 3 . The porosity values support non cohesiveness which aided the good flow that was observed. Good flowability is desirable in powders/granules to enable proper die filling and production of tablets with minimal variation in weight.

Table 3: Properties of Ibuprofen granules

\begin{tabular}{lllll}
\hline Batch/Parameter & Batch I & Batch II & Batch III & Batch IV \\
\hline Bulk density (g/ml) & $0.36 \pm 0.01$ & $0.36 \pm 0.02$ & $0.36 \pm 0.01$ & $0.37 \pm 0.01$ \\
Tapped density (g/ml) & $0.42 \pm 0.03$ & $0.41 \pm 0.04$ & $0.41 \pm 0.02$ & $0.43 \pm 0.07$ \\
Flow rate (g/s) & $9.63 \pm 0.54$ & $8.79 \pm 0.61$ & $7.50 \pm 0.25$ & $7.39 \pm 1.04$ \\
Angle of repose ${ }^{\circ}$ ) & $29.00 \pm 0.20$ & $27.00 \pm 0.50$ & $30.00 \pm 0.10$ & $30.10 \pm 0.01$ \\
Hausner's quotient & $1.17 \pm 0.01$ & $1.14 \pm 0.01$ & $1.14 \pm 0.06$ & $1.16 \pm 0.02$ \\
Carr's index (\%) & $14.28 \pm 0.33$ & $12.19 \pm 0.91$ & $12.19 \pm 0.52$ & $13.95 \pm 1.04$ \\
True density (g/ml) & $1.76 \pm 0.11$ & $1.71 \pm 0.05$ & $2.07 \pm 0.01$ & $1.92 \pm 0.20$ \\
Porosity $(\%)$ & $79.55 \pm 0.11$ & $78.95 \pm 0.13$ & $82.61 \pm 0.10$ & $80.73 \pm 0.05$ \\
\hline
\end{tabular}

\section{In Vitro Ibuprofen Tablet Parameters \\ Physical properties}

The results of some of the physical properties are shown in Table 4. The ibuprofen tablets had no physical defects that could be detected visually.

\section{Uniformity of weight}

The result of the assessment of the tablets for uniformity of weight is shown in Table 4. The tablets showed minimal variation in weight and were found to comply with British Pharmacopoeia specifications for uncoated tablets that weigh more than $250 \mathrm{mg}$. The permissible percentage variation for such tablets is stipulated to be within $\pm 5 \%$ of the given tablet weight 30 .

\section{Hardness}

The hardness of the ibuprofen tablets were in the range of $5.32 \pm 0.41-6.33 \pm 0.36 \mathrm{kgF}$ (Table 4). All the tablets met with the British Pharmacopoeia recommendation for uncoated tablets which is given as $\geq 4.00 \mathrm{kgF}$. Such hardness values imply good mechanical strength and physical integrity of the tablets.

\section{Disintegration time}

The disintegration time result show that all the ibuprofen tablets disintegrated within $7 \mathrm{~min}$ (Table 4) which is quite good for the different batches of tablets. The upper permissible limit by the British Pharmacopoeia is $15 \mathrm{~min}$ therefore, the tablets passed the test 30 . Uncoated tablets are expected to disintegrate within $15 \mathrm{~min}$ after oral ingestion to enable release of the active pharmaceutical ingredient for dissolution and possible absorption in the gastro intestinal tract.

\section{Friability}

The ibuprofen tablets were poorly friable as all the batches had friability in the range of $0.63 \pm 0.10-0.99 \pm 0.01 \%$. This is a good attribute as it is an indication of the ability of the tablets to withstand the abrasive stresses that would be encountered during packaging, transportation and handling during use. Uncoated tablets are expected to have friability of $\leq 1.00 \%{ }^{30,34}$. The ibuprofen tablets passed the friability test.

\section{Thickness}

The thickness of the ibuprofen tablets are shown in Table 4. There is no significant difference $(p>0.05)$ in the thickness of the different tablets. This suggests that there was fair uniform filling of the granules into the dies as well as uniform compression pressure during the tableting of the granules.

\section{Hardness friability ratio}

The hardness friability ratio is a parameter that is used to assess the mechanical strength of the tablets in relation to the effects abrasive activities can have on the tablet. The order of strength of the ibuprofen tablets were: Batch II > Batch III > Batch IV > Batch I (tablets containing potato > yellow corn > corn starch BP > cassava starches respectively) (Table 4). 
Table 4: Physical parameters of ibuprofen tablets

\begin{tabular}{lllll}
\hline Batch/Parameter & Batch I & Batch II & Batch III & Batch IV \\
\hline Uniformity of weight (mg) & $601.37 \pm 0.04$ & $610.92 \pm 0.03$ & $605.02 \pm 0.04$ & $596.61 \pm 0.03$ \\
Hardness (kgF) & $5.32 \pm 0.41$ & $6.33 \pm 0.36$ & $5.97 \pm 0.11$ & $5.80 \pm 0.40$ \\
Disintegration time (min) & $4.92 \pm 1.38$ & $1.77 \pm 0.82$ & $2.75 \pm 0.50$ & $6.27 \pm 1.85$ \\
Friability (\%) & $0.91 \pm 0.01$ & $0.63 \pm 0.01$ & $0.69 \pm 0.02$ & $0.71 \pm 0.10$ \\
Thickness (mm) & $4.45 \pm 0.15$ & $4.50 \pm 0.20$ & $4.47 \pm 0.10$ & $4.48 \pm 0.10$ \\
HFR & 5.85 & 10.05 & 8.65 & 8.16
\end{tabular}

${ }^{*}$ HFR is Hardness Friability Ratio

\section{Assay of ibuprofen tablets}

Results of the assay of the ibuprofen tablets are shown in Figure 1. All the samples contained ibuprofen ranging from $99.50 \pm 1.25-99.75 \pm 1.50 \%$ based on the $400 \mathrm{mg}$ per tablet targeted content during formulation. At $10 \mathrm{~min}$ of release, there was a significant difference $(\mathrm{p}<0.05)$ for all the batches except the tablets containing cassava and corn starch BP ( $p$ > 0.05). At $30 \mathrm{~min}$, there was also a significant difference $(\mathrm{p}<0.05)$ in the release properties and more than $90 \%$ of the ibuprofen had been released from the tablets. Statistical evaluation at $60 \mathrm{~min}$ show that significant differences $(p<0.05)$ existed in all the batches except between batches containing cassava and corn starch BP (p > 0.05). The tablets for all the batches met with the British Pharmacopoeia specification for ibuprofen which is given as $95-105 \%$ of the label claim ${ }^{30}$. The ibuprofen tablets passed the assay/content of active ingredient test.

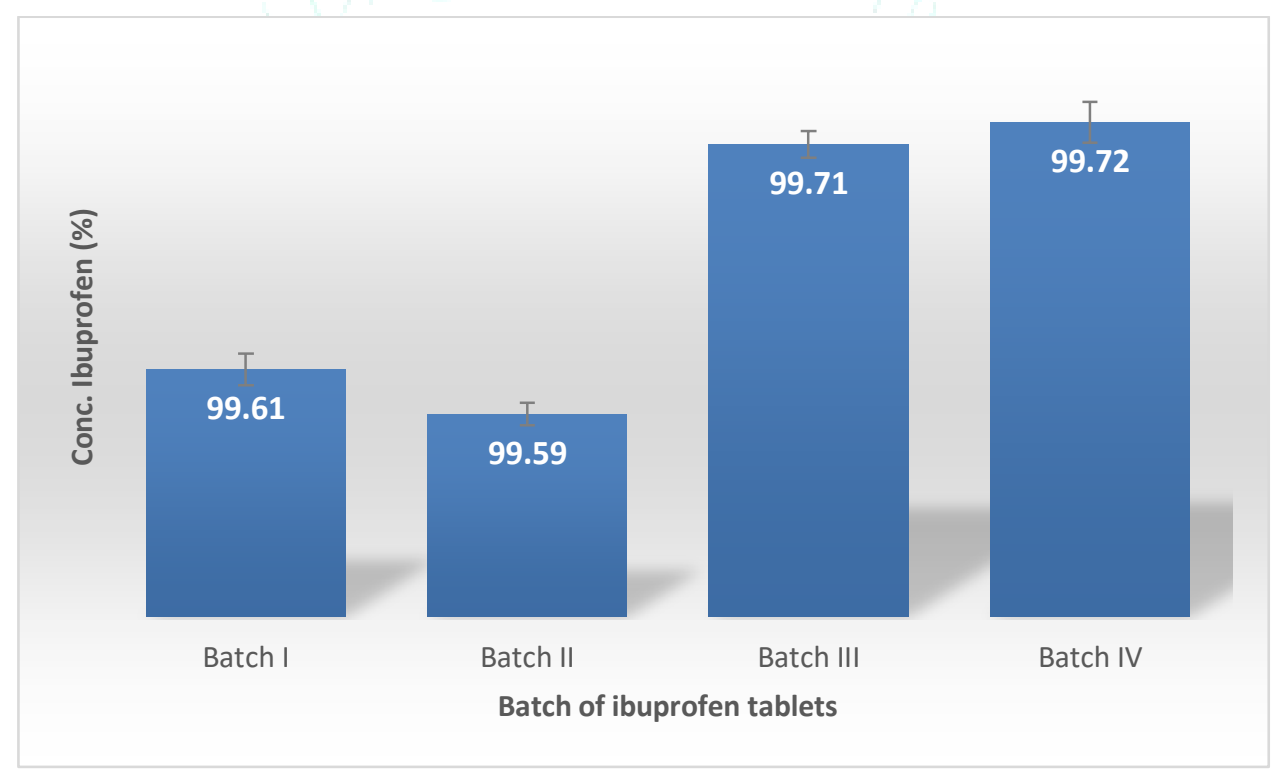

Figure 1: Bar chart of the assay of the ibuprofen tablets.

\section{Dissolution of ibuprofen}

The drug release profile of the ibuprofen tablets containing starches of cassava, potato, yellow corn and corn starch BP is shown in Fig. 2. There was a fast release of ibuprofen from the tablets within $10 \mathrm{~min}$, thereafter the release increased gradually until $30 \mathrm{~min}$. Most of the tablets released more than $80 \%$ of their ibuprofen content within $30 \mathrm{~min}$. Statistically, at 10 min there was a significant difference $(\mathrm{p}<$ 0.05 ) in the release of ibuprofen for all the batches of tablets except between tablets containing yellow corn starch and corn starch BP that had no significant difference ( $p>0.05)$. At $30 \mathrm{~min}$, there was a significant difference $(\mathrm{p}<0.05)$ amongst all the batches. Comparatively, Batch IV of the ibuprofen tablets which contained corn starch BP was the most released within $15 \mathrm{~min}$. It was closely followed by the tablets containing yellow corn starch (Batch III) while the tablets containing potato starch were the least released. All the batches met with BP requirements which stipulates that up to $80 \%$ of ibuprofen must be released from the tablets within $30 \mathrm{~min} 30$. 


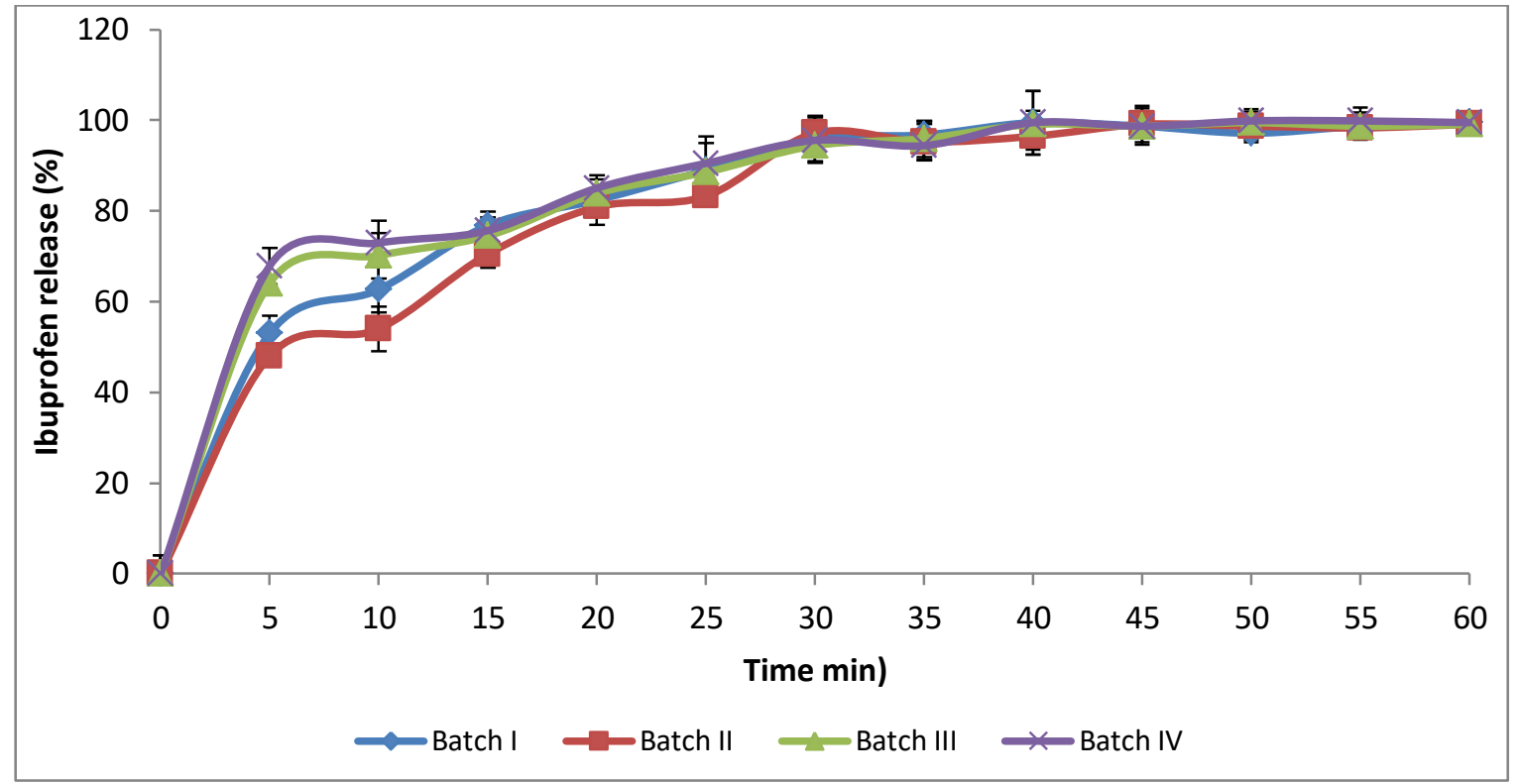

Fig.2: Dissolution profile of ibuprofen tablets containing cassava, potato, yellow corn and corn starch BP

\section{CONCLUSION}

The starches extracted from cassava, potato and yellow corn had the characteristics of starch. Their $\mathrm{pH}$ were close to neutral and their heavy metal content were within acceptable limits. They swelled and hydrated well in water showing that they would act as disintegrants in tablet formulations. Ibuprofen granules formulated with the starches as disintegrants had good flow and compressibility. The tablets had minimal weight variation, good mechanical strength, friability and disintegration times. The content of ibuprofen in the tablets, and its release therefrom met with acceptable British Pharmacopoeia set limits. The data obtained from the different evaluation parameters containing the derived starches from cassava, potato and yellow corn compared well with corn starch BP which was used as comparing standard. These starches served as good disintegrants in ibuprofen tablets.

\section{REFERENCES}

1.Quodbach J, Kleinebudde P. A critical review on tablet disintegration. Pharmaceutical Development and Technology. 2016; 21(6):763-774.

2.Gavura, S. "What's all that other stuff in my medicine?". ScienceBased Medicine. Archived from the original in 2019. Retrieved February 21, 2019.

3.Markl D, Zeitler JA, A Review of Disintegration Mechanisms and Measurement Techniques, Pharm Res., 2017; 34(5): 890-917

4.Desai PM, Liew CV, Heng PWS, Review of Disintegrants and the Disintegration Phenomena. Journal of Pharmaceutical Sciences. 2016; 105(9):2545-2555

5.Khairnar DA, Anantwar SP, Chaudhari CS, Shelke PA, Superdisintegrants: An emerging paradigm in orodispersible tablets. International Journal of Biopharmaceutics. 2014, 5(2):119-28.

6.Nayak AK, Manna K, "Current developments in orally disintegrating tablet technology," Journal of Pharmaceutical Education and Research, 2011; 2 (1):21-34.

7.Emeje MO, Rodrigues A. In: Valdez B, editor. Starch: From Food to Medicine, Scientific, Health and Social Aspects of the Food Industry. InTech; 2012, ISBN: 978-953-307-916-
8.Cheetham NWH, Tao L.. Variation in crystalline type with amylose content in maize starch granules: An X-ray powder diffraction study. Carbohydrate Polymers 1998;36(4):277-284

9.Tonukari NJ, Cassava and the future of starch, Electronic J. Biotechnol., 2004; 7:5-8.

10.0memu AM, Akpan I, Bankole MO, Teniola OD, Hydrolysis of raw tuber starches by amylase of aspergillus niger AM07 isolated from the soil, Afr. J. Biotechnol.,2005; 4:19-25

11.Vimala B, Hariprakash B, Nambisan B, Breeding of sweet potato for enhanced nutritional status and biofortification. Fruit, Veg.Cereal Sci. Biotech. 2012; 6(1):93-105.

12.Woolfe JA. Sweet Potato: An Untapped Food Resource, Cambridge, UK, Cambridge University Press, 1992, p. 643.

13.Huang AS, Tanudjaja L, Lum D, The Content of beta-carotene and dietary fibre in 18 sweet potato varieties grown in Hawaii. Journal of Food Composition and Analysis, 1999; 12:147-151.

14.Low J, Walker T, Hijmans R. The potential impact of orangefleshed sweet potatoes on vitamin A intake in Sub-Saharan Africa. The VITAA Project, vitamin A and orange-fleshed sweet potatoes in Sub-Saharan Africa, Nairobi, Kenya, 2007. Available online: http://www.pdfs.semanticscholrs.org. Accessed on 26/05//2020.

15.Torres AF, Slegers PM, Noordan - Boot CMM, Dolstra DV, Louis VB, Anton JBV, Richard GFT, Luisa M, Maize feed stocks with improved digestibility reduce the costs and environmental impacts of biomass pretreatment and saccharification. Biotechnology for biofuels, 2016; 9:63.

16. Halford GM, Lordkipanidzé M, Watson SP, 50 th anniversary of the discovery of ibuprofen: an interview with Dr. Stewart Adams. Platelets, 2012; 23 (6):415-22

17.Shailender Mohan, Compression physics of pharmaceutical powders: a review. Int. J Pharm Sci. Res, 2012, 3(6): 1580-1592.

18.Aly Nada, Bernd W. Mueller, Saleh M. Al-Saidan, Improving the physical and chemical properties of ibuprofen. Pharmaceutical Technology, 2005; 29:11

19.Kirchheiner J, Brockmöller J, Clinical consequences of cytochrome P450 2C9 polymorphisms. Clin. Pharmacol. Ther. 2005; 77:1-16.

20.Joe Tucci, Emily Bandiera, Rima Darwiche, Zeljko Medos, Robert Nashed, David Trinh Paracetamol and ibuprofen for paediatric pain and fever. Journal of Pharmacy Practice and Research, 2009; 39(3): =223-225. 
21.WHO List of Essential Medicines (April 2013) http://www.who.int/medicines/publications/essentialmedicine s /en/ Retrieved 11th August, 2019.

22.Knutson, C. A., Evaluation of variations in amylose-iodine absorbance spectra. Carbohydr. Polym. 1999; 42, 65 -72.

23.Kornblum SS, Stoopak SB. A New Tablet Disintegrant Agent Crosslinked Polyvinylpyrrolidone, J. Pharm. Sci., 1973; 62(1):4349.

24.Bowen EF, Vadino AW. A simple method for differentiating starches. Drug Dev. Ind. Pharm. 1984; 10:505-511

25.Ansel CH, Popovich NG, Allen LV. Ansel's pharmaceutical dosage forms and drug delivery systems. New York: Lippincott Williams and Wilkins, New York. 2005; 189.

26.0deku OA, Awe 00, Popoola B, Odeniyi MA, Itiola OA. Compression \& mechanical properties of tablet formulations containing corn, sweet potato and cocoyam starches as binders, Pharm. Technol., 2005; 29(4): 82-90.

27.Jones TM, Pilpel N, The flow properties of granular magnesia. J. Pharm. Pharmacol, 1996; 18: 81-93.
28.Staniforth JN, "Powder Flow” In: Aulton, M.E., Pharmaceutics: The Science of Dosage Form Design, ELBS, Churchill Livingstone, London: 1988, p. 105.

29.Neuman SB, The Flow Properties of Powders, Advances in Pharmaceutical Sciences, Academic Press, London: 1967, pp. 181 $-188$.

30.British Pharmacopoeia, Vol.II, Her Majesty Stationary Office, University Press, Cambridge, 2012; A326 - 327.

31.Vargas-Aguilar P, Flours and starches made from cassava (yuca), yam, sweet potatoes and ñampi: functional properties and possible applications in the food industry. Tecnología en Marcha. Edición especial ingles: 2016; 86-94.

32.Kunle 00, Starch source and its impact on Pharmaceutical Applications, Intech, 2019, DOI: http://dx.doi.org/10.5772/intechopen.89811

33.Thoorens G, Krier F, Leclercq B, Evrad B, Microcrystalline cellulose, a direct compression binder in a quality by design environment - A review. Int. J. Pharmaceutics, 2014; 473:64-72

34.United States Pharmacopoeia, The United States Pharmacopoeial Convention, Rockville, USA, 2009, pp.358, 688-689. 